\title{
Anti-/pro-apoptotic effects of hesperetin against 7,12- dimetylbenz(a)anthracene-induced alteration in animals
}

\author{
EUN JEONG CHOI and GUN-HEE KIM \\ Plant Resources Research Institute, Duksung Women's University, 419 Ssangmun-dong, \\ Tobong-ku, Seoul 132-714, Republic of Korea
}

Received September 1, 2010; Accepted October 25, 2010

DOI: 10.3892/or.2010.1105

\begin{abstract}
This study investigated the anticancer effects of hesperetin on 7,12-dimethylbenz(a)anthracene (DMBA)treated animals and explored its anticancer mechanism. The experiment consisted of two parts. First, Sprague-Dawley rats were given hesperetin daily at a dose of $50 \mathrm{mg} / \mathrm{kg}$ for 8 weeks after a single dose of DMBA $(100 \mathrm{mg} / \mathrm{kg})$. As controls, rats were divided into vehicle alone and DMBA alone groups. Secondly, ICR mice were given hesperetin daily at a dose of 10 and $50 \mathrm{mg} / \mathrm{kg} \mathrm{BW} /$ day for 7 weeks before a single dose of DMBA (34 mg/kg/week). In rats with DMBA-induced mammary gland tumors, hesperetin pretreatment significantly reduced the tumor burden and PCNA overexpression. The administration of hesperetin significantly inhibited mammary gland carcinoma from developing by restoring the decreased $\mathrm{Bcl}-2$ and increased Bax expression. By contrast, in the livers of mice treated with DMBA, obvious DNA fragmentation was observed. Moreover, apoptosis-related gene expression in the livers of the mice differed from that in mammary gland carcinomas in rats. These changes were restored in mice treated with hesperetin, indicating the inhibition of apoptosis. Based on these results, hesperetin may act not only as a proapoptotic agent, but also as an antiapoptotic agent, depending on the circumstance.
\end{abstract}

\section{Introduction}

Free radicals and/or ROS are thought to be involved in a number of pathophysiological conditions. The most deleterious effects of ROS, which include lipid peroxidation, protein oxidation, and oxidative DNA damage, may have an etiological or prognostic role in cancer (1). Recently, the antiproliferative and proapoptotic effects of antioxidants

Correspondence to: Dr Eun Jeong Choi, Plant Resources Research Institute, Duksung Women's University, 419 Ssangmun-dong, Tobong-ku, Seoul 132-714, Republic of Korea

E-mail: ejchoi@duksung.ac.kr

Key words: antioxidant, anti-apoptosis, DMBA, hesperetin, proapoptosis, in vivo from plants have been explored in an attempt to create new chemopreventive and chemotherapeutic agents. Multiple studies have demonstrated that flavonoids can suppress cancer through their antioxidative, antiproliferative, and proapoptotic effects $(2,3)$. The ability of flavonoids to promote apoptosis makes them very attractive candidates in the development of anticancer drugs.

Among these flavonoids, hesperetin (3',5,7-trihydroxy-4methoxyflavanone), which is occurs as hesperidin (its glycoside form) in nature, and is found in fruit sources, including various citrus species $(4,5)$. Although few in vitro studies have compared hesperetin with hesperidin, we previously found that hesperetin inhibits cellular proliferation, the induction of a cell cycle arrest at $G_{1}$, and apoptosis in human breast MCF-7 cancer cells (6). Based on these data, hesperetin may be a good candidate for an anticancer drug; however, no in vivo data are available concerning its possible anticancer effects.

Therefore, we investigated the anticancer effects of hesperetin in an animal model using a chemical carcinogen. Moreover, the mechanism of the anticancer effects of hesperetin via antioxidation and the induction of apoptosis was explored.

First, the proapoptotic effect of hesperetin was investigated in a well-defined rat mammary gland tumor model. To induce mammary carcinoma in rats, we used polycyclic aromatic hydrocarbon 7,12-dimethylbenz(a)anthracene (DMBA), a well-known chemical carcinogen that produces mammary tumors that are morphologically and histologically similar to those found in humans. A single dose of $100 \mathrm{mg} / \mathrm{kg}$ DMBA in SD rats will produce a mammary carcinoma yield of $100 \%$ roughly 8 weeks post-treatment (7).

Second, the effects of hesperetin in modulating the cancerous response to oxidative stress was investigated in the livers of mice exposed to DMBA for 1 week after hesperetin pretreatment. DMBA also acts as an indirect carcinogen. Although the liver is not a target of DMBA-induced carcinogenesis, DMBA is first metabolized by cytochrome $\mathrm{P}_{450}$ to form carcinogenic metabolites such as diol epoxides that can be transported to the mammary glands, resulting in DMBADNA adducts $(8,9)$. In addition, DMBA induces substantial oxidative damage as result in the formation of ROS such as peroxides, hydroxyl, and superoxide anion radicals in organs such as the liver and mammary glands (10-12). This study was designed to evaluate the potential benefit of 
hesperetin as a chemopreventive and/or chemotherapeutic agent for human cancer cells.

\section{Materials and methods}

Hesperetin treatment and sample preparation. All animals (Central Lab, Animal Inc., Seoul, Korea) were acclimated for 1 week under standard environmental condition with AIN 93M diet (Dyets, Bethlehem, PA, USA) and allowed free access to water. The experiment consisted of two parts during 8 weeks. In the first, Sprague-Dawley rats were randomly divided into three groups, each comprising of eight animals. Hesperetin (Sigma) was dissolved in water and administered orally to rats at a dose of $50 \mathrm{mg} / \mathrm{kg} \mathrm{BW}$ for 8 weeks after a single dose of DMBA $(100 \mathrm{mg} / \mathrm{kg})$. As controls, rats were divided into vehicle alone and DMBA alone groups. In the second part, ICR mice were orally administered hesperetin daily at a dose of 10 and $50 \mathrm{mg} / \mathrm{kg}$ BW for 7 weeks before a single dose of DMBA (34 $\mathrm{mg} / \mathrm{kg} /$ week). After hesperetin administration was followed for 1 week continuously. The control groups were the same as above and each group comprised of six mice. The period and dosage of the DMBA treatments are thought to increase the incidence of cancer and cancer development. DMBA (Sigma) was dissolved in corn oil and was also administered orally to all animals. The hesperetin treatment dosage was determined based on a previous study, where serum glutamic-oxaloacetic transaminase (GOT) and glutamic-pyruvic transaminase (GPT), biomarkers of hepatic function, were not affected in mice treated with a hesperatin dose of $50 \mathrm{mg} / \mathrm{kg} \mathrm{BW}$ for 12 weeks.

Animal care in this study conformed to the Guide for the Care and Use of Laboratory Animals published by the U.S. National Institutes of Health. At the end of experiment, mice were rapidly anesthetized using ether at $6 \mathrm{~h}$ after final administration of hesperetin. Their livers and mammary gland tumors were isolated, blotted, weighed, frozen in liquid nitrogen and stored at $-70^{\circ} \mathrm{C}$ until assayed. Mammary gland tumor volume was measured using calipers and calculated as following formula: $\mathrm{V}=4 / 3 \pi r^{3}$.

Immunoblotting assay. Samples were homogenizing with in RIPA buffer (1\% NP-40, $150 \mathrm{mM} \mathrm{NaCl}, 0.05 \%$ DOC, $1 \%$ SDS, $50 \mathrm{mM}$ Tris, $\mathrm{pH}$ 7.5) containing protease inhibitor and lysed for $1 \mathrm{~h}$ at $4^{\circ} \mathrm{C}$. The supernatant was separated by centrifugation, and protein concentration was determined by Bradford protein assay kit II (Bio-Rad Laboratories, CA, USA). Proteins (50 $\mu \mathrm{g} /$ well) denatured with sample buffer were separated by $10 \%$ SDS-polyacrylamide gel. Proteins were transferred onto nitrocellulose membranes $(0.45 \mu \mathrm{m})$. The membranes were blocked with a $1 \%$ BSA solution for $3 \mathrm{~h}$ and washed twice with PBS containing 0.2\% Tween-20, and incubated with the primary antibody overnight at $4^{\circ} \mathrm{C}$. Antibodies against Bcl-2, Bax, cleaved caspase-9 (37 kDa), cleaved caspase-3 (19 kDa), cleaved PARP (85 kDa) and B-actin were purchased from Santa Cruz Biotechnology Inc., Santa Cruz, CA, USA) and used to probe the separate membranes. The next day, the immunoreaction was continued with the secondary goat anti-rabbit horseradish-peroxidaseconjugated antibody after washing for $2 \mathrm{~h}$ at room tempe-

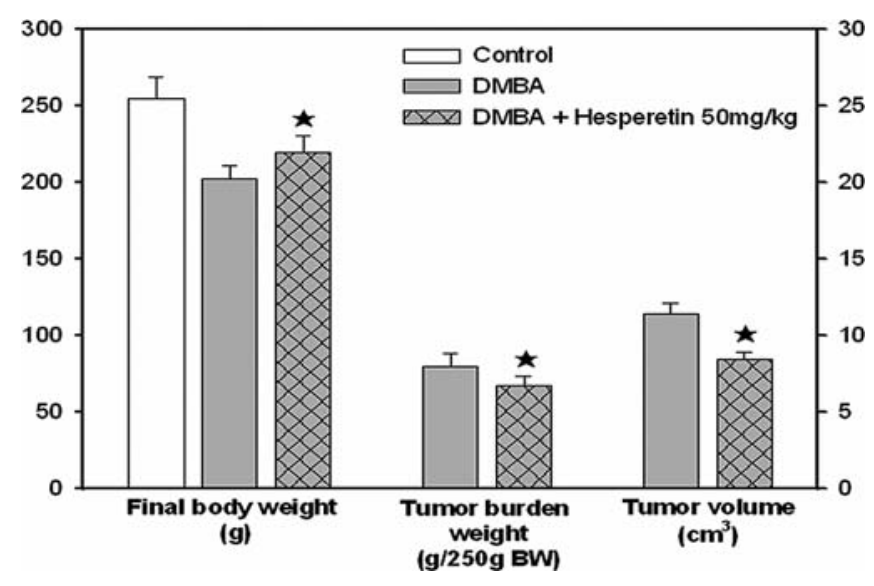

Figure 1. Effects of hesperetin on body weight, tumor weight and volume in rats mammary gland tumors. Sprague-Dawley rats were given hesperetin daily at a dose of $50 \mathrm{mg} / \mathrm{kg}$ for 8 weeks after a single dose of DMBA $(100 \mathrm{mg} / \mathrm{kg})$. As controls, rats were divided into vehicle alone and DMBA alone groups. Values are presented as mean $\pm \mathrm{SD}(\mathrm{n}=8)$. ${ }^{*} \mathrm{P}<0.05$, significantly different from the respective control group (DMBA-treated or untreated).

rature. The specific protein bands were detected by Opti4CN Substrate kit (Bio-Rad).

DNA fragmentation assay. Samples were homogenized in lysis buffer (20 mM EDTA, 0.5\% CHAPS, $100 \mathrm{mM}$ Tris, $\mathrm{pH}$ 8.0) and were incubated at $37^{\circ} \mathrm{C}$ with RNase A at a concentration of $200 \mu \mathrm{g} / \mathrm{ml}$ for $1 \mathrm{~h}$, followed by treatment overnight with proteinase $\mathrm{K}$ at $55^{\circ} \mathrm{C}$. DNA was extracted from $25,000 \times$ g centrifugation fraction using phenol-chloroform method as follow. A phenol:chloroform:isoamyl alcohol mixture $(25: 24: 1)$ was used to remove the proteins. After protein removal, the suspension was incubated with $100 \%$ cold ethanol containing $0.1 \mathrm{M}$ sodium acetate for $24 \mathrm{~h}$. The precipitated DNA was washed with $70 \%$ ethanol, resuspended, run on $1.5 \%$ agarose gel at $70 \mathrm{~V}$ for $1.5 \mathrm{~h}$ and then visualized under UV light.

ROS generation assay. Samples were homogenized in ice cold isolation buffer ( $320 \mathrm{mM}$ sucrose, $1 \mathrm{mM}$ EGTA, $10 \mathrm{mM}$ Tris, $\mathrm{pH}$ 7.4) and centrifuged for $5 \mathrm{~min}$ at $1,000 \mathrm{x} \mathrm{g}$. Then, the supernatant was transferred and centrifuged for $5 \mathrm{~min}$ at $7,800 \mathrm{x}$ g. The pellet was resuspended in isolation buffer containing $19 \%$ Percoll and centrifuged for $10 \mathrm{~min}$ at $11,200 \mathrm{x}$. The pellet form samples were washed again with cold PBS and processed for ROS generation analysis. Reactive oxygen species (ROS) were determined by using fluorescent probe $\mathrm{H}_{2}$ DCF-DA (Molecular Probes, Eugene, OR). $\mathrm{H}_{2}$ DCF-DA is enzymatically hydrolyzed by intracellular esterases to form non-fluorescent $\mathrm{H}_{2} \mathrm{DCF}$, which is then rapidly oxidized to form highly fluorescent DCF in the presence of ROS. Briefly, the cells were fixed in absolute ethanol and stored at $-20^{\circ} \mathrm{C}$ for later analysis. Cells were washed again in cold PBS and incubated with $1 \mu \mathrm{M} 2^{\prime}, 7^{\prime}-$ dichlorofluorescein diacetate (DCFH-DA, Sigma) at $37^{\circ} \mathrm{C}$ for 15 min in the dark. The cells were analyzed a FACSCalibur instrument (BD Biosciences, San Jose, CA). The DCF oxidation was determined using the median fluorescence intensity on the FL1 detector. 


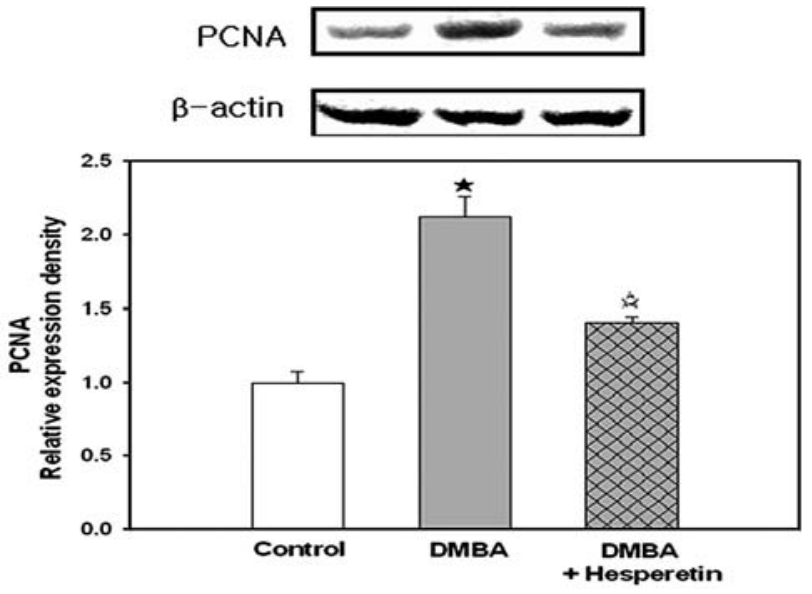

Figure 2. Effects of hesperetin on PCNA expression in rats mammary gland tumors. Sprague-Dawley rats were given hesperetin daily at a dose of $50 \mathrm{mg} / \mathrm{kg}$ for 8 weeks after a single dose of DMBA $(100 \mathrm{mg} / \mathrm{kg})$. As controls, rats were divided into vehicle alone and DMBA alone groups. Values are presented as mean $\pm \mathrm{SD}(\mathrm{n}=8)$. ${ }^{\star} \mathrm{P}<0.05$, significantly different from the control group. ${ }^{\text {t }} \mathrm{P}<0.05$, significantly different from the DMBA-treated group.

Statistical analyses. Data were analyzed by unpaired Student's t-test or one-way analysis of variance followed by Dunnett's multiple comparison test (SigmaStat, Jandel, San Rafael, CA, USA). For all comparisons, differences were considered statistically significant at $\mathrm{P}<0.05$.

\section{Results}

Effects of hesperetin on body weight and tumor weight in rats with DMBA-induced mammary gland tumors. A significant decrease in body weight was observed in the DMBA-treated group compared with the control group $(\mathrm{P}<0.05)$. The average weight of the induced mammary gland tumors was $7.98 \mathrm{~g} / 250 \mathrm{~g} \mathrm{BW}$ (Fig. 1). Hesperetin significantly reduced the tumor burden by $19.6 \%$ as compared to rats treated with DMBA only $(\mathrm{P}<0.05)$. Tumor volume of hesperatin-treated rats $\left(1.14 \mathrm{~cm}^{3}, \mathrm{P}<0.05\right)$ was also significantly reduced as compared to the DMBA group $\left(0.84 \mathrm{~cm}^{3}\right)$.

Effects of hesperetin on the expression of PCNA in rats with DMBA-induced mammary gland tumors. PCNA expression in the mammary gland tumors of rats treated with DMBA was significantly increased by 2.1 times compared with control rats (Fig. 2, $\mathrm{P}<0.05$ ). The level of overexpression was reduced by $\sim 50 \%$ in the hesperetin-pretreated group.

Pro-apoptotic effects of hesperetin on DMBA-induced mammary gland tumor cells. Hesperetin treatment significantly increased p53 expression by $21.1 \%$, as compared to the DMBA group. There was no statistically significant difference in $\mathrm{p} 53$ expression between the DMBA group and controls. DMBA increased Bcl-2 expression in the mammary gland tumors of mice treated with DMBA by $54.1 \%$ compared with the control group (Fig. 3, $\mathrm{P}<0.05$ ), whereas hesperetin treatment restored $\mathrm{Bcl}-2$ expression to near-normal levels. Also, Bax expression was significantly decreased by $18.8 \%$ in mice treated with DMBA compared with the control

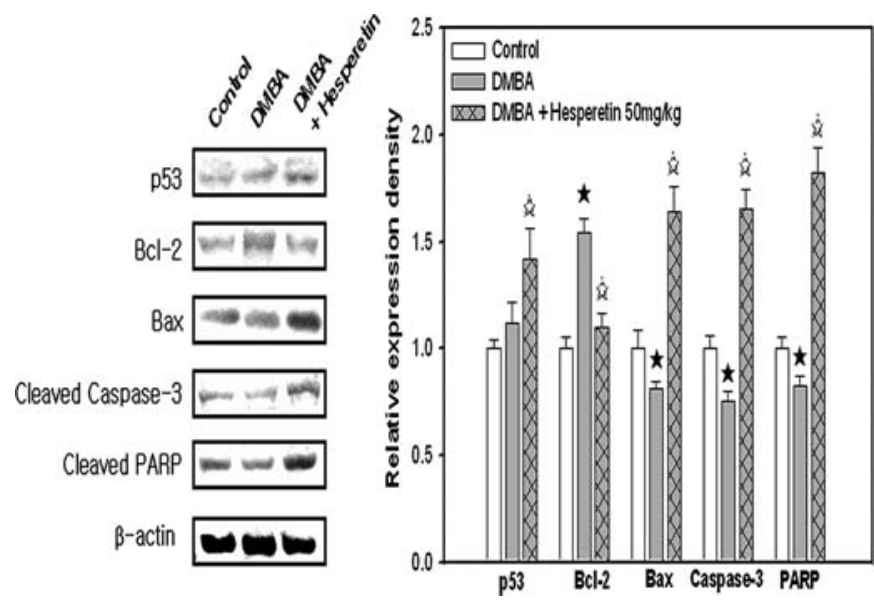

Figure 3. Effect of hesperetin on p53, Bcl-2, Bax, cleaved caspase-3 and PARP expressions in rats mammary gland tumors. Sprague-Dawley rats were given hesperetin daily at a dose of $50 \mathrm{mg} / \mathrm{kg}$ for 8 weeks after a single dose of DMBA $(100 \mathrm{mg} / \mathrm{kg})$. As controls, rats were divided into vehicle alone and DMBA alone groups. Values are presented as mean \pm SD $(n=8) .{ }^{\star} \mathrm{P}<0.05$, significantly different from the control group. ${ }^{\star} \mathrm{P}<0.05$, significantly different from the DMBA-treated group.

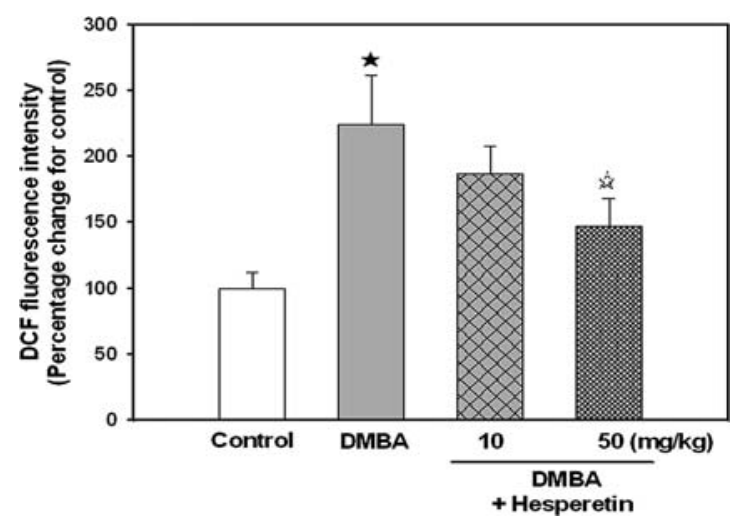

Figure 4. Effect of hesperetin on ROS generation in liver of mice treated with DMBA. ICE mice were given hesperetin daily at a dose of $50 \mathrm{mg} / \mathrm{kg}$ BW/day for 3 weeks after a single dose of DMBA (34 mg/kg). As controls, rats were divided into vehicle alone and DMBA alone groups. Values are presented as mean $\pm \mathrm{SD}(\mathrm{n}=6)$. All data are reported as the percentage change in comparison with the vehicle-only group, which were arbitrarily assigned $100 \%$ viability.

group. Similarly, cleaved caspase- 3 and PARP expression was decreased by 24.8 and $17.6 \%$, respectively, compared with the control values. Bax, cleaved caspase- 3 , and PARP expression by hesperetin was elevated approximately 2-fold compared with DMBA groups.

Effects of hesperetin on body weight and food intake in mice treated with $D M B A$. No statistically significant differences in body weight were observed between the DMBA group versus controls at the end of the experimental periods. Oral pre-administration of hesperetin to mice did not affect body weight or food intake (data not shown).

Effects of hesperetin on the ROS generation in mice treated with DMBA. ROS levels in the livers of mice exposed to 


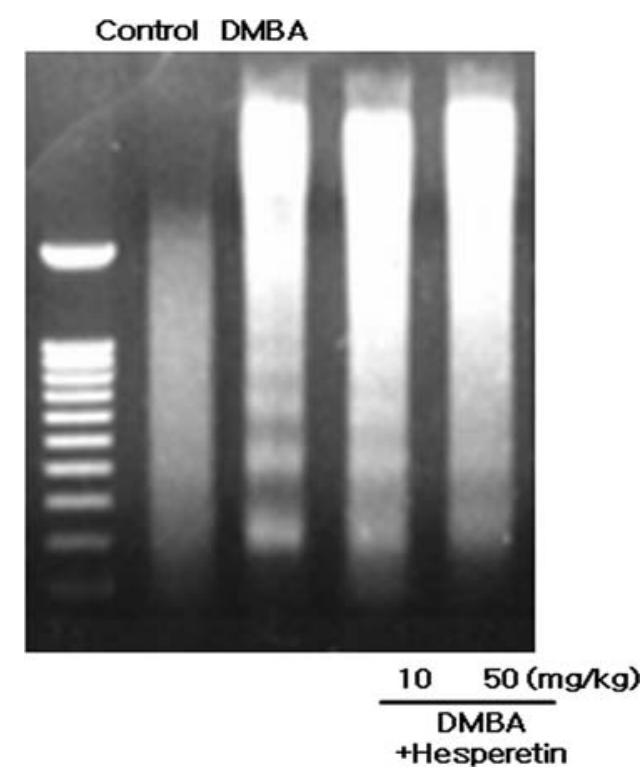

Figure 5. Effect of hesperetin on DMBA-induced DNA fragmentation in liver of mice treated with DMBA. ICE mice were given hesperetin daily at a dose of $50 \mathrm{mg} / \mathrm{kg} \mathrm{BW} /$ day for 3 weeks after a single dose of DMBA $(34 \mathrm{mg} / \mathrm{kg})$. As controls, rats were divided into vehicle alone and DMBA alone groups. Values are presented as mean $\pm \operatorname{SD}(n=6)$.

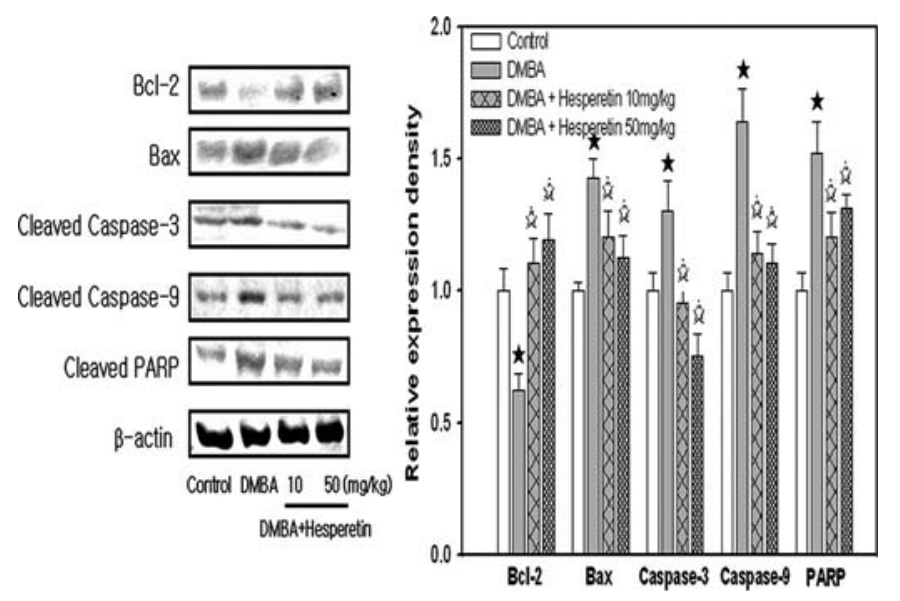

Figure 6. Effect of hesperetin on Bcl-2, Bax, cleaved caspase-3 and PARP expressions in liver of mice treated with DMBA. ICE mice were given hesperetin daily at a dose of $50 \mathrm{mg} / \mathrm{kg}$ BW/day for 3 weeks after a single dose of DMBA (34 mg/kg). As controls, rats were divided into vehicle alone and DMBA alone groups. Values are presented as mean \pm SD $(n=6)$. ${ }^{\star} \mathrm{P}<0.05$, significantly different from the control group. ${ }^{\star} \mathrm{P}<0.05$, significantly different from the DMBA-treated group.

DMBA were significantly increased: 2.2 times that of controls (Fig. 4, $\mathrm{P}<0.05$ ). In mice treated with the higher dose of hesperatin, however, this induction was reduced by $\sim 34.5 \%$.

Anti-apoptotic effects of hesperetin in mice treated with $D M B A$. DNA fragmentation was observed in the hepatic cells of mice exposed to DMBA (Fig. 5). Hesperetin pretreatment prevented DNA fragmentation efficiently, but not completely, in a dose-dependent manner. In the liver of mice exposed to
DMBA, we observed a $37.5 \%$ decrease in $\mathrm{Bcl}-2$ expression and a $42.5 \%$ increase in Bax expression compared with the control group (Fig. 6). In addition, cleaved caspase-3 and PARP expression was increased by 30.2 and $52.1 \%$ in the DMBA-treated group, respectively, compared with the control group. These changes were reversed by pretreatment with hesperetin; Bcl-2 expression was increased by 76.3 and $90.8 \%$, as compared to the DMBA group after hesperetin pretreatment doses of 10 and $50 \mathrm{mg} / \mathrm{kg} \mathrm{BW}$, respectively. Hesperetin significantly decreased Bax, cleaved caspase-3, caspase-9, and PARP expression at the lower dose $(10 \mathrm{mg} / \mathrm{kg}$ $\mathrm{BW})$, regardless of exposure time $(\mathrm{P}<0.05)$.

\section{Discussion}

We investigated the mechanism through which hesperatin mediates its anticancer effects in the animal model. Using SD rats with mammary gland tumors induced by DMBA, tumor formation was decreased in the hesperetin-treated group in comparison with rats that received only DMBA. Cellular proliferation is an integral part of carcinogenesis, with important roles in several steps of the carcinogenic process, including initiation, promotion, and progression $(13,14)$. The expression of PCNA, a nuclear protein that is present during $\mathrm{S}$ phase, was used as a marker of cellular proliferation in the mammary glands tumor of DMBA-treated rats. PCNA expression has also been used to measure the proliferation rate of tumors. PCNA expression was significantly increased in mammary gland tumors induced by DMBA compared with that in control rats. This is consistent with previous reports that showed PCNA overexpression in a wide range of human tumors $(15,16)$, as well as in DMBAinduced mammary gland tumors $(17,18)$. Hesperetin treatment significantly reduced PCNA overexpression by $>50 \%$. These data suggest that hesperetin decreases cell proliferation in mammary gland tumors through the reduction of PCNA expression.

We previously reported that hesperetin induced G1-phase cell cycle arrest in vitro through the regulation of CDK4 and $\mathrm{p} 21^{\mathrm{Cip} 1}$, suggesting that involvement of the apoptotic process is one possible mechanism through which hesperetin mediates its anticancer effects. In the present study, hesperetin treatment significantly increased the expression of p53, an upstream target of $\mathrm{p} 21^{\mathrm{Cip} 1}$, consistent with our previous data. The tumor suppressor gene p53 is regarded as a key factor in the balance between cell survival and cell death, via regulation of both the $G_{1}$ and $G_{2} / M$ portions of the cell cycle (19). Activation of p53 in response to DNA damage would lead to cell cycle arrest and inhibition of cell proliferation, thereby preventing tumor formation $(20,21)$.

Bcl-2 family proteins are critical regulators of the apoptotic pathway and control both mitochondrial permeability and cytochrome c expression $(22,23)$. The Bcl-2 family contains several major antiapoptotic members, including $\mathrm{Bcl}-\mathrm{x}(\mathrm{L})$ and $\mathrm{Bcl}-2$, as well as the major proapoptotic proteins Bax and Bak. In the DMBA-treated group, Bcl-2 expression was increased, whereas Bax expression was decreased. It has been reported that $\mathrm{Bcl}-2$ overexpression inhibits the transcriptional activation of Bax (24). Overexpression of antiapoptotic proteins such as Bcl-2 may 
contribute to tumor formation in DMBA-treated SD rats. Hesperetin treatment significantly induced apoptosis in the mammary gland tumors by increasing proapoptotic Bax expression, with a subsequent increase in the expression of cleaved caspase-3. Caspases, which comprise a family of cysteine proteases, are the central mediators of programmed cell death. Caspase- 3 is a frequently activated death protease that catalyzes the specific cleavage of many key cellular proteins $(25,26)$. Also, PARP is another characteristic hallmark of apoptosis, and PARP overexpression was also induced by hesperetin.

Flavonoids act as general cell growth inhibitors and apoptosis inducers, which makes them prime candidates in the development of new anticancer compounds (27-29). Also, several studies have shown that flavonoids are protective against DMBA-induced rat mammary tumorigenesis $(30,31)$. Thus, the proapoptotic capacity of hesperetin in mammary gland tumors may be valuable in the development of new anticancer drugs.

In our second experimental model, we assessed the induction of oxidative liver damage in mice by DMBA because the production of ROS in hepatocytes is significantly elevated by DMBA. This is consistent with DMBA having a dose- and time-dependent effect on the production of $\mathrm{H}_{2} \mathrm{O}_{2}$ in rat liver microsomes (32). The formation of ROS during DMBA metabolism induces oxidative damage, the first step involved in mutagenesis, carcinogenesis and ageing. It is well established that ROS-mediated DNA damage is associated with carcinogenesis $(33,34)$. Hesperetin pretreatment inhibited the production of ROS in a dose-dependent manner.

The changes induced by DMBA led to the induction of apoptosis. DNA fragmentation was observed in the livers of mice treated with DMBA. DNA fragmentation is a hallmark of apoptosis and a positive association between DNA fragmentation and apoptosis has been reported (35). The induction of DNA fragmentation by DMBA was reduced by hesperetin in a dose-dependent fashion. This is consistent with previously reported data showing that Swiss albino mice treated with DMBA exhibited increased levels of apoptosis in the liver within 8 days of treatment (12); similarly, apoptosis was detected 24 and $36 \mathrm{~h}$ after DMBA treatment $(80 \mathrm{mg} / \mathrm{kg})$ in the adrenal cortexes of the mice (36).

Several recent reports have suggested that antioxidants play a major role in the development of cancer. Several mechanisms for the chemopreventive effects of antioxidants have been proposed, including the suppression of ROS generation and the activation of an antioxidant defense system during both the initiation and promotion of cancer (37-40). It has been reported that increased levels of antioxidants decrease ROS levels and inhibit apoptosis (41). We found that hesperetin pretreatment restored the expression of Bcl-2, Bax, cleaved caspase-3, caspase-9, and PARP to their normal levels, regardless of the dose. It has been shown that apoptosis in the adrenal cortex preceded necrosis after treatment of rats with DMBA (42). That is, in pathophysiological condition apoptosis can lead to induction of inflammation because of the onset of secondary necrosis, although apoptosis can occur in a physiological condition without inflammation $(43,44)$. Previous studies report that caspase- 9 is activated by reactive oxygen species (45). In the present study, hesperetin pretreatment remarkably inhibited the activation of caspase- 9 by DMBA. This hespertinmediated modulation of apoptosis-related gene expression in mice with DMBA-induced apoptosis may be the result of a protective mechanism in the liver.

In summary, our data support previous in vitro results that suggest the usefulness of hesperetin as an anticancer agent $(6,46)$. In our in vivo study, hesperetin induced the apoptosis in mammary gland tumors. In addition, hesperetin showed a hepatic protective effect via the reduction of apoptosis in mice with oxidative liver damage. Thus, hesperetin may act not only as a pro-apoptotic agent, but also as an antiapoptotic agent, depending on the circumstance. These 'twofaced' characteristics of hesperetin may be useful in the development of chemopreventive and/or chemotherapeutic agents.

\section{Acknowledgements}

This study was supported by Priority Research Centers Program through the National Research Foundation of Korea (NRF) funded by the Ministry of Education, Science and Technology (2009-0094018).

\section{References}

1. Musarrat J, Arezina-Wilson J and Wani AA: Prognostic and aetiological relevance of 8-hydroxyguanosine in human breast carcinogenesis. Eur J Cancer 32A: 1209-1214, 1996.

2. Hollman PC and Katan MB: Health effects and bioavailability of dietary flavonols. Free Radic Res 3: S75-S80, 1999.

3. Jung KJ, Wallig MA and Singletary KW: Purple grape juice inhibits 7,12-dimethylbenz[a] anthracene (DMBA)-induced rat mammary tumorigenesis and in vivo DMBA-DNA adduct formation. Cancer Lett 233: 279-288, 2006

4. Garg A, Garg S, Zaneveld LJ and Singla AK: Chemistry and pharmacology of the Citrus bioflavonoid hesperidin. Phytother Res 15: 655-669, 2001.

5. Gil-Izquierdo A, Gil MI, Ferreres F and Tomás-Barberán FA: In vitro availability of flavonoids and other phenolics in orange juice. J Agric Food Chem 49: 1035-1041, 2001.

6. Choi EJ: Hesperetin induced G1-phase cell cycle arrest in human breast cancer MCF-7 cells: involvement of CDK4 and p21. Nutr Cancer 59: 115-119, 2007.

7. Huggins C, Grand LC and Brillantes FP: Mammary cancer induced by a single feeding of polymucular hydrocarbons, and its suppression. Nature 189: 204-207, 1961.

8. Maltzman TH, Christou M, Gould MN and Jefcoate CR: Effects of monoterpenoids on in vivo DMBA-DNA adduct formation and on phase I hepatic metabolizing enzymes. Carcinogenesis 12: 2081-2087, 1991 .

9. Harvey RG, Dai Q, Ran C and Penning TM: Synthesis of the o-quinones and other oxidized metabolites of polycyclic aromatic hydrocarbons implicated in carcinogenesis. J Org Chem 69: 2024-2032, 2004.

10. Izzotti A, Camoirano A, Cartiglia C, Grubbs CJ. Lubet RA, Kelloff GJ and De Flora S: Patterns of DNA adduct formation in liver and mammary epithelial cells of rats treated with 7,12dimethylbenz(a)anthracene, and selective effects of chemopreventive agents. Cancer Res 59: 4285-4290, 1999.

11. Anbuselvam C, Vijayavel K and Balasubramanian MP. Protective effect of Operculina turpethum against 7,12-dimethyl benz(a)anthracene induced oxidative stress with reference to breast cancer in experimental rats. Chem Biol Interact 168: 229-236, 2007.

12. Prasad S, Kalra N and Shukla Y: Hepatoprotective effects of lupeol and mango pulp extract of carcinogen induced alteration in Swiss albino mice. Mol Nutr Food Res 51: 352-359, 2007.

13. Barrett JC: Mechanisms of multistep carcinogenesis and carcinogen risk assessment. Environ Health Perspect 100: 9-20, 1993 
14. Manna S, Chakraborty T, Damodaran S, Samanta K, Rana B and Chatterjee M: Protective role of fish oil (Maxepa) on early events of rat mammary carcinogenesis by modulation of DNAprotein crosslinks, cell proliferation and p53 expression. Cancer Cell Int 7: 6, 2007.

15. Sallinen PK, Haapasalo HK, Visakorpi T, Helén PT, Rantala IS, Isola JJ and Helin HJ: Prognostication of astrocytoma patient survival by Ki-67 (MIB-1), PCNA, and S-phase fraction using archival paraffin-embedded samples. J Pathol 174: 275-282, 1994.

16. Ehrmann J Jr, Kolár Z, Vojtesek B, Kala M, Komenda S and Oulton A: Prognostic factors in astrocytomas: relationship of p53, MDM-2, BCL-2 and PCNA immunohistochemical expression to tumor grade and overall patient survival. Neoplasma 44: 299-304, 1997

17. Manjanatha M, Shelton S, Bishop M, Lyn-Cook L and Aidoo A: Dietary effects of soy isoflavones daidzein and genistein on 7,12-dimethylbenz[a]anthracene-induced mammary mutagenesis and carcinogenesis in ovariectomized Big Blue transgenic rats. Carcinogenesis 27: 1970-1979, 2006.

18. Kumaraguruparan R, Seshagiri PB, Hara Y and Nagini S: Chemoprevention of rat mammary carcinogenesis by black tea polyphenols: modulation of xenobiotic-metabolizing enzymes, oxidative stress, cell proliferation, apoptosis, and angiogenesis. Mol Carcinog 46: 797-806, 2007

19. Agarwal ML, Agarwal A, Taylor WR and Stark GR: p53 controls both the G2/M and the G1 cell cycle checkpoints and mediates reversible growth arrest in human fibroblasts. Proc Natl Acad Sci USA 92: 8493-8497, 1995

20. Park M, Chae HD, Yun J, Jung M, Kim YS, Kim SH, Han MH and Shin DY: Constitutive activation of cyclin B1-associated cdc2 kinase overrides p53-mediated G2-M arrest. Cancer Res 60: $542-545,2000$

21. Lepik D, Jaks V, Kadaja L, Varv S and Maimets T: Electroporation and carrier DNA cause p53 activation, cell cycle arrest, and apoptosis. Anal Biochem 318: 52-59, 2003.

22. Oakes SA, Lin SS and Bassik MC: The control of endoplasmic reticulum-initiated apoptosis by the BCL-2 family of proteins. Curr Mol Med 6: 99-109, 2006.

23. van Delft MF and Huang DC: How the Bcl-2 family of proteins interact to regulate apoptosis. Cell Res 16: 203-213, 2006

24. Lucken-Ardjomande S and Martinou JC: Regulation of Bcl-2 proteins and of the permeability of the outer mitochondrial membrane. CR Biol 328: 616-631, 2005.

25. Porter AG and Jänicke RU: Emerging roles of caspase-3 in apoptosis. Cell Death Differ 6: 99-104, 1999.

26. Abu-Qare AW and Abou-Donia MB: Biomarkers of apoptosis: release of cytochrome $\mathrm{c}$, activation of caspase-3, induction of 8-hydroxy-2'-deoxyguanosine, increased 3-nitrotyrosine, and alteration of p53 gene. J Toxicol Environ Health B Crit Rev 4: 313-332, 2001.

27. Galati G and O'Brien PJ: Potential toxicity of flavonoids and other dietary phenolics: significance for their chemopreventive and anticancer properties. Free Radic Biol Med 37: 287-303, 2004.

28. Tsuda H, Ohshima Y, Nomoto H, Fujita K, Matsuda E, Iigo M, Takasuka N and Moore MA: Cancer prevention by natural compounds. Drug Metab Pharmacokinet 19: 245-263, 2004

29. Kandaswami C, Lee LT, Lee PP, Hwang JJ, Ke FC, Huang YT and Lee MT: The antitumor activities of flavonoids. In Vivo 19: 895-909, 2005.
30. Kim H, Hall P, Smith M, Kirk M, Prasain JK, Barnes S and Grubbs C: Chemoprevention by grape seed extract and genistein in carcinogen-induced mammary cancer in rats is diet dependent. J Nutr 134: S3445-S3452, 2004.

31. Samy RP, Gopalakrishnakone P and Ignacimuthu S: Anti-tumor promoting potential of luteolin against 7,12-dimethylbenz(a) anthracene-induced mammary tumors in rats. Chem Biol Interact 164: 1-14, 2006

32. Frenkel K: The role of active oxygen species in biological damage and the effect of some chemopreventive agents. In: Protease Inhibitors as Cancer Chemopreventive Agents. Troll W and Kennedy AR (ed). Plenum Press, New York, pp227-249, 1993.

33. Kang DH: Oxidative stress, DNA damage, and breast cancer. AACN Clin Issues 13: 540-549, 2002.

34. Valko M, Rhodes CJ, Moncol J, Izakovic M and Mazur M: Free radicals, metals and antioxidants in oxidative stress-induced cancer. Chem Biol Interact 160: 1-40, 2006.

35. Sigounas G, Hooker JL, Li W, Anagnostou A and Steiner M: S-allylmercaptocysteine, a stable thioallyl compound, induces apoptosis in erythroleukemia cell lines. Nutr Cancer 28: 153-159, 1997.

36. Fu X, Latendresse JR, Muskhelishvili L, Blaydes BS and Delclos KB: Dietary modulation of 7,12-dimethylbenz[a] anthracene (DMBA)-induced adrenal toxicity in female Sprague-Dawley rats. Food Chem Toxicol 43: 765-774, 2005.

37. Zheng Q, Hirose Y, Yoshimi N, Murakami A, Koshimizu K, Ohigashi H, Sakata K, Matsumoto Y, Sayama Y and Mori H: Further investigation of the modifying effect of various chemopreventive agents on apoptosis and cell proliferation in human colon cancer cells. J Cancer Res Clin Oncol 128: 539-546, 2002.

38. Leung HW, Kuo CL, Yang WH, Lin CH and Lee HZ: Antioxidant enzymes activity involvement in luteolin-induced human lung squamous carcinoma $\mathrm{CH} 27$ cell apoptosis. Eur J Pharmacol 534: 12-18, 2006.

39. Hsu CL and Yen GC: Induction of cell apoptosis in 3T3-L1 preadipocytes by flavonoids is associated with their antioxidant activity. Mol Nutr Food Res 50: 1072-1079, 2006.

40. Jeong YJ, Choi YJ, Kwon HM, Kang SW, Park HS, Lee M and Kang YH: Differential inhibition of oxidized LDL-induced apoptosis in human endothelial cells treated with different flavonoids. Br J Nutr 93: 581-591, 2005.

41. Agostini M, Di Marco B, Nocentini G and Delfino DV: Oxidative stress and apoptosis in immune diseases. Int J Immunopathol Pharmacol 15: 157-164, 2002.

42. Tsuta K, Shikata N, Kominami S and Tsubura A: Mechanisms of adrenal damage induced by 7,12-dimethylbenz (alpha) anthrancene in female Sprague-Dawley rats. Exp Mol Pathol 70: $162-172,2001$

43. Jaeschke H and Lemasters JJ: Apoptosis versus oncotic necrosis in hepatic ischemia/reperfusion injury. Gastroenterology 125: 1246-1257, 2003.

44. Raffray M and Cohen GM: Apoptosis and necrosis in toxicology: a continuum or distinct modes of cell death? Pharmacol Ther 75: 153-177, 1997.

45. Kim JY and Park JH: ROS-dependent caspase-9 activation in hypoxic cell death. FEBS Lett 549: 94-98, 2003.

46. Choi EJ, Kim GD, Chee KM and Kim GH: Effects of hesperetin on vessel structure formation in mouse embryonic stem (mES) cells. Nutrition 22: 947-951, 2006. 